\title{
REGIONAL ENVIRONMENTAL QUALITY: AN OPTIMAL INDUSTRY MIX TO MINIMIZE POLLUTION: COMMEN T
}

\section{H. Bruce Throckmorton}

\author{
Tennessee Technological University
}

The authors state that "the prime concern... is the environmental impact of economic development based on tourism" (p. 2). However, the constraints used in the linear programming model place priority on environmental impact rather than economic development. The conclusions suggest that the minimization of pollution would necessarily yield either a lower per capita income in the study area or a lower sales volume or both than that which existed in 1968-1969.

The desire to gain economic growth and to preserve the environment are admirable goals. The attainment of these goals while not reducing employment in any industry is also commendable. However, the only growth in employment occurs in tourism which the paperimplies to be a relatively low income industry.

There are several questions which arise concerning the conclusions that were reached. The linear programming approach to the problem seems justifiable such that my remarks pertain primarily to the conclusions.

1) Is not the situation of employment during the study period as good a solution, if not better, than the derived by the model? There would be less total employment, the difference being all intourism; but per capita income would be higher. It is not conceivable that this would yield a greater amount of pollution than the so-called optimal solution. There appears to be a concept of negative marginal pollution in the attainment of such an optimum.

2) Might not the lower per capita income contribute to outmigration from the area such that industry would decline still further? At least, there would be little, if no, incentive for in-migration. This might impose severe restrictions on economic development.

3) The model apparently did not consider the possibility of industry shifts in employment. The dynamic feature of development of new industries also was not included (of course, these concepts do violate constraints 4). Shifts from high polluting industries such as chemicals necessarily would work to reduce pollution and yet maintain, if not increase, per capita income. The development of new "clean" industries in the area might also contribute toward the minimization of pollution.

4) The solution yields lower tax revenue for educational purposes. One could convincingly argue that both environmental quality and economic development are functionally related to quality education. A decline of financial support for public education might carry with it the beginning of both an environmental and economic decline for the study area.

In conclusion, the solution does not achieve what I would call an optimum position. The conclusions show the economic impact of environmental quality based on tourism rather than the converse. The authors are aware the constraints other than full employment might yield a superior result. I hope that further research will result in a situation allowing for economic stability or growth along with minimization of pollution. 